\title{
Prevalence and correlates of achieving recommended physical activity levels among children living in rural South Asia-A multi-centre study
}

Krithiga Shridhar $^{1 *}$, Christopher Millett ${ }^{2}$, Anthony A. Laverty ${ }^{2}$, Dewan Alam³ ${ }^{3}$ Amit Dias ${ }^{4}$, Joseph Williams ${ }^{5}$ and Preet K. Dhillon'

\begin{abstract}
Background: We report the prevalence of recommended physical activity levels (RPALs) and examine the correlates of achieving RPALs in rural South Asian children and analyse its association with anthropometric outcomes.

Methods: This analysis on rural South Asian children aged 5-14 years $(n=564)$ is a part of the Chronic Disease Risk Factor study conducted at three sites in India (Chennai $n=146$; Goa $n=218$ ) and Bangladesh (Matlab; $n=200$ ). Data on socio-demographic and lifestyle factors (physical activity (PA); diet) were collected using an interviewer-administered questionnaires, along with objective anthropometric measurements. Multivariate logistic regression models were used to examine whether RPALs (active travel to school (yes/no); leisure-time PA $\geq 1 \mathrm{~h} /$ day; sedentary-activity $\leq 2 \mathrm{~h} /$ day) were associated with socio-demographic factors, diet and other forms of PA. Multivariate linear regression models were used to investigate associations between RPALs and anthropometrics (BMI- and waist z-scores).

Results: The majority of children (71.8\%) belonged to households where a parent had at least a secondary education. Two-thirds (66.7\%) actively travelled to school; $74.6 \%$ reported $\geq 1$ h/day of leisure-time PA and $55.7 \%$ had $\leq 2 \mathrm{~h} /$ day of sedentary-activity; $25.2 \%$ of children reported RPALs in all three dimensions. Older (10-14 years, $\mathrm{OR}=2.0 ; 95 \% \mathrm{Cl}: 1.3,3.0)$ and female $(\mathrm{OR}=1.7 ; 95 \% \mathrm{Cl}: 1.1,2.5)$ children were more likely to travel actively to school. Leisure-time $P A \geq 1 \mathrm{~h} /$ day was more common among boys $(\mathrm{OR}=2.5 ; 95 \% \mathrm{Cl}$ : 1.5, 4.0), children in Matlab, Bangladesh $(\mathrm{OR}=3.0 ; 95 \% \mathrm{Cl}: 1.6,5.5)$, and those with higher processed-food consumption (OR $=2.3$; $95 \%$ Cl: 1.2, 4.1). Sedentary activity $\leq 2 \mathrm{~h}$ /day was associated with younger children (5-9 years, OR = 1.6; 95 \% Cl: 1.1, 2. 4), children of Goa (OR=3.5; $95 \% \mathrm{Cl}: 2.1,6.1)$ and Chennai ( $\mathrm{OR}=2.5 ; 95 \% \mathrm{Cl}: 1.5,4.3)$ and low household education $(\mathrm{OR}=2.1 ; 95 \% \mathrm{Cl}: 1.1,4.1)$. In multivariate analyses, sedentary activity $\leq 2 \mathrm{~h} /$ day was associated with lower BMl-z-scores ( $\beta=-0.3 ; 95 \% \mathrm{Cl}:-0.5,-0.08)$ and lower waist-z-scores ( $\beta=-1.1 ; 95 \% \mathrm{Cl}:-2.2,-0.07)$.
\end{abstract}

Conclusion: Only one quarter of children in these rural areas achieved RPAL in active travel, leisure and sedentary activity. Improved understanding of RPAL in rural South Asian children is important due to rapid socio-economic transition.

Keywords: Physical activity, Children, South Asia, LMIC, Active travel, Sedentary activity, BMI-z- score, Anthropometrics, Waist- z- score

\footnotetext{
* Correspondence: g.krithiga@phfi.org

${ }^{1}$ Centre for Chronic Conditions and Injuries, Public Health Foundation of

India, 4th Floor, Plot.No.47, Sector 44, Gurgaon 122002, Haryana, India

Full list of author information is available at the end of the article
} 


\section{Background}

Physical activity in children improves cardio-respiratory, muscular, bone and mental health [1-4]. It decreases the likelihood of overweight and obesity and the development of non-communicable diseases (NCDs) in childhood and adulthood [1-4]. Some programming of adult-onset NCDs can take place during childhood $[1,5]$ and are preventable through early life-style modifications [6]. Physical activity is an established modifiable risk exposure, for which earlier tracking and intervention will help in attaining a beneficial effect of physical activity patterns in adult life [1]. The World Health Organization (WHO) recommends $1 \mathrm{~h}$ of moderate to vigorous physical activity for children everyday [4]. Sedentary activity less than $2 \mathrm{~h}$ per day is beneficial for physical, social and academic performance of children $[1-3,7]$. 'Active travel to school' such as walking and cycling (versus use of motorized transport) improves cardiovascular fitness and thus is recommended as well [8].

Although data in children are limited in South Asia [9], physical activity patterns and the risks associated with various forms of physical inactivity (motorized transport to school, long TV viewing, no outdoor games etc.) have been reported in children and adolescents in some urban settings [1, 3, 9-19]. Across the various regions of urban South Asia a high prevalence of physical inactivity (18.3 to $67.4 \%$ ) have been reported among children [1, 9]. Transition in physical activity patterns (i.e., from being active to more sedentary) among children is also an increasing concern globally [20, 21]. Data from rural South Asia are sparse [9], partly because physical inactivity or sedentary behaviour is perceived to be a problem of urban environments and among more affluent communities. India and Bangladesh are low-and-middle income countries (LMICs) where nearly three-fourths of children aged between 5 and 14 years live in rural areas $[22,23]$. NCD risk factors, [24-26] and sedentary behaviour are frequently reported in rural adult populations, [27] yet, there are no strategic guidelines for physical activity in children in these regions and physical activity data in children from rural areas will help inform policy decisions $[28,29]$.

In this study, we report the prevalence and correlates of recommended physical activity levels (RPALs) through leisure-time physical activity (LTPA) and active travel alongside sedentary activity from three different rural regions of India (Chennai and Goa) and Bangladesh (Matlab). We examine associations between different forms of physical activity and measures of adiposity.

\section{Methods}

\section{Study population}

Study participants were part of the Chronic Disease Risk Factor (CDRF) study. The CDRF is a multi-centre, cross-sectional study of NCD risk factors and outcomes among rural populations in South Asia [30, 31]. The survey was conducted by the South Asia Network for Chronic Diseases (SANCD), Public Health Foundation of India in partnership with local organizations at the study sites: Sangath in Goa, Voluntary Health Services in Chennai, and the International Centre for Diarrheal Disease Research, Matlab in Bangladesh. At each site, sampling frames that reflected local demographics and access to healthcare were constructed. Each site was selected on the basis of being a typical rural community in each setting, reflecting the local demographics and having access to healthcare facilities to support the collection of physical measurements. At each site, households in consecutive village sections, from the healthcare centre outwards, were sampled until households numbered at least 250 and terminated at the end of a street, block or cluster of homes within a village $(n=308$ households in Matlab, 309 in Goa, 257 in Chennai). All household residents of $2+$ years resident in the area for at least 6 months of the year were invited to participate $(n=$ 1143 in Matlab, 1212 in Goa, 940 in Chennai). Response rates were $92.9 \%$ in Goa, $96.1 \%$ in rural Chennai and $96.1 \%$ in Matlab. This analysis included only children aged 5 to 14 years who provided informed consent to participate in the CDRF project. A total of $n=564$ children aged 5 to 14 years were enrolled in the study from rural regions of India ( $n=146$ from Chennai; $n=218$ from Goa) and Bangladesh ( $n=200$ from Matlab). An urban population was also sampled in Chennai, but excluded from our analysis as numbers $(n=76)$ were insufficient for urban-rural comparisons.

\section{Data collection}

Data were collected from November, 2011 to March, 2013 in Chennai, October, 2011 to March, 2013 in Goa and June, 2011 to May, 2012 in Matlab. Each consenting participant received a structured, interviewer-administered questionnaires, which was translated and back translated to the local language of the study site (Tamil in Chennai; Konkani in Goa; Bengali in Bangladesh). Household-level data were collected on non-health expenditures, utilities, health insurance, exposure to indoor biomass fuel and monthly consumption of sugar, salt and oil. Individuallevel data were captured by directly administering the questionnaires to children from 10 to 14 years and to the mother or other care-taker if the child was 2 to 9 years of age. Details on personal factors (e.g., siblings, order of birth, health status, quality of life), medical history, use of health care services, lifestyle habits (e.g., diet, physical activity), and outcomes (e.g., disability) were collected. Physical measurements such as anthropometrics (e.g., height, weight, waist, hip and arm circumferences) were collected by trained personnel. Socio-economic status (SES) for the household was calculated based 
on tertiles from total monthly expenditures for Indian sites and total household asset score for Matlab, Bangladesh. The highest household education status was based on the highest educational level reported among all family members living in the household. Missing data varied between 1 \% (e.g., household education status) to $11.5 \%$ (e.g., SES) for different variables.

\section{Outcome variables}

Physical activity measurements in children were adapted from the 'Indian Migration Study' Physical Activity Questionnaire (IMS-PAQ) which was validated in adults aged 18+ years across 18 different Indian states [32]. It includes questions about mode of transport to school (e.g., motorized vehicle (car/bus/auto/two-wheeler), bicycle or walk), leisure-time physical activities (e.g., outdoor games/sports both at school and apart from school such as walking, badminton, jogging, cricket) and sedentary activities involving sitting, apart from at school (e.g., reading, watching television, listening to radio, carom, computer/video games). Details about the physical activity in terms of duration per activity (in minutes) and frequency (number of times per day/week/month) were also collected. We were able to capture the same and additional information than World Health Organisation's Global School-based Health Survey [33] that is culturally appropriate for Indian settings.

Binary variables for mode of travel to school (yes/no any reported mode of active travel), leisure- time physical activity (LTPA) at home and at school, and sedentary activity outside school hours were created. The cut-off level for leisure-time physical activity was based on WHO recommended levels of physical activity for children aged 5 to 17 years (i.e., $\geq 1$ h everyday) [4]. The cut-off level for sedentary activity was based on a systematic review of sedentary behavior and health indicators in school-aged children and youth (5-17 years) i.e., $\leq 2 \mathrm{~h}$ daily [7].

Secondary outcome variables were anthropometric measurements of children taken by trained personnel. The measurements included two of standing height (to the nearest $1 \mathrm{~mm}$, using a portable stadiometer (Leicester)), two of weight (to the nearest $100 \mathrm{~g}$, using portable digital scales (Tanita), with the participants in light clothing and no shoes), two of each of waist and hip circumference (to the nearest $1 \mathrm{~mm}$, using a taut plastic tape). BMI-z scores are calculated for WHO-reference values using STATA-Macros for children 5 years of age and WHO2007 for children 6-14 years of age which represents external standardization of the study with the WHO reference population [34]. Waist z-scores are residuals adjusted for age and sex which represent internal standardization of the study population. The outcome variables were continuous and adjusted for age and sex.

\section{Statistical analysis}

A standard descriptive summary was expressed as percentages or as the mean and standard deviation (SD) and comparisons between sites made using chi-square or ANOVA tests. Logistic regression models were used to examine socio-demographic and dietary correlates of different types of physical activity/inactivity that are part of RPALs (mode of transport to school, leisure-time physical activity and sedentary activity). Linear regression models were used to examine associations between physical activity status (mode of transport to school, leisure-time physical activity and sedentary activity) and two measures of adiposity: BMI-z and waist-z scores. Models were adjusted for site, SES, highest level of education in the household, processed food consumption, fruit and vegetable consumption and other types of physical activity. All analyses were conducted using STATA version 10 (StataCorp, USA).

\section{Results}

\section{Summary of participant characteristics}

A total of $n=564$ children aged 5 to 14 years from rural populations of India and Bangladesh were included in our analysis: 146 from Chennai, 218 from Goa and 200 from Matlab. A summary of their socio-demographic characteristics, physical activity patterns, diet and weight-related outcomes are presented in Table 1 . Nearly half (48.4 \%) were girls. Rural children in Chennai were more likely to live in a household with higher education: 77.6, 73.6 and $60 \%$ of children lived in a household with at least one member educated to secondary school level (Chennai, Goa and Matlab, respectively). Two-thirds of children (66.7 \%) actively travelled to school across all sites $(69.2 \%$ Chennai, India; 69.4 in Goa, India and 62 \% in Matlab, Bangladesh). The majority of children were involved in leisure- time physical activity for $\geq 1 \mathrm{~h}$ every day, with the highest prevalence rates (80.2\%) reported in Matlab (59.8 and $78.8 \%$ for Chennai and Goa). Children in Matlab, Bangladesh were much less likely to have $\leq 2 \mathrm{~h}$ sedentary activity per day (37\%) compared to children in Chennai $(64.8 \%)$ and Goa (67.3\%). Fruit and vegetable consumption was low across all sites ( $87.8 \%$ consumed $<5$ servings/ day). The consumption of processed food ( $\geq 1$ serving per day) was higher in Matlab and Chennai (44.0\% and $34.9 \%$ respectively, $p<0.0001$ ). While Goan children recorded the highest waist-z-scores (mean (SD) 1.3(6.3), $p<0.0001)$, BMI-z-scores were similar across sites (mean (SD) -1.3(1.1)).

\section{Correlates of achieving recommended levels of physical activity}

The correlates of recommended physical activity levels (RPALs) in rural children aged 5-14 yrs are presented in Tables 2 and 3 as proportions and multivariate adjusted odds ratios respectively. 
Table 1 Socio-demographic, physical activity, diet and anthropometric profile of rural South Asian children aged 5-14 years

\begin{tabular}{|c|c|c|c|c|c|}
\hline Mean(SD)/\% & $\begin{array}{l}\text { Chennai } \\
n=146(25.9 \%)\end{array}$ & $\begin{array}{l}\text { Goa } \\
n=218(38.6 \%)\end{array}$ & $\begin{array}{l}\text { Matlab } \\
n=200(35.5 \%)\end{array}$ & $p$-value ${ }^{a}$ & $\begin{array}{l}\text { Total } \\
n=564\end{array}$ \\
\hline \multicolumn{6}{|l|}{ Age group (years) } \\
\hline $5-9$ years & 42.4 & 46.3 & 45.0 & \multirow[t]{2}{*}{0.7} & 44.8 \\
\hline $10-14$ years & 57.5 & 53.6 & 55.0 & & 55.1 \\
\hline \multicolumn{6}{|l|}{ Sex } \\
\hline$\%$ Boys & 52.7 & 56.8 & 45.0 & 0.05 & 51.6 \\
\hline \multicolumn{6}{|l|}{ Highest household education status } \\
\hline $0-5$ years of education & 22.4 & 26.4 & 34.0 & & 28.1 \\
\hline 6 to 12 years of education & 66.4 & 61.1 & 51.5 & \multirow[t]{2}{*}{$<0.0001$} & 59.0 \\
\hline Graduate/Post graduate & 11.2 & 12.5 & 14.5 & & 12.8 \\
\hline \multicolumn{6}{|l|}{ Socio-economic status ${ }^{\mathrm{b}}(\mathrm{SES})$} \\
\hline Low & 45.9 & 11.2 & 34.9 & \multirow{3}{*}{$<0.0001$} & 28.7 \\
\hline Medium & 41.6 & 29.1 & 36.1 & & 34.9 \\
\hline High & 12.4 & 59.7 & 28.9 & & 36.5 \\
\hline \multicolumn{6}{|l|}{ Mode of transport to school } \\
\hline Active transport (walk/bicycle) & 69.2 & 69.4 & 62.0 & & 66.7 \\
\hline Motorized transport (car, bus, auto, two-wheeler) & 30.8 & 30.6 & 38.0 & \multirow[t]{2}{*}{0.1} & 33.3 \\
\hline \multicolumn{5}{|l|}{ Leisure-time physical activity } & \\
\hline$<1$ h/day & 40.1 & 21.2 & 19.8 & & 25.4 \\
\hline 1-2 h/day & 52.2 & 46.9 & 43.1 & & 46.8 \\
\hline $2.1-4$ h/day & 6.8 & 29.2 & 31.9 & \multirow[t]{3}{*}{$<0.0001$} & 24.6 \\
\hline $4.1-6$ h/day & 0.7 & 1.5 & 5.0 & & 2.6 \\
\hline$>6 \mathrm{~h} /$ day & 0.0 & 1.0 & 0.0 & & 0.3 \\
\hline \multicolumn{6}{|l|}{ Sedentary activity } \\
\hline$<1$ h/day & 17.2 & 19.2 & 11.5 & & 15.9 \\
\hline $1-2$ h/day & 47.5 & 48.0 & 25.5 & \multirow[t]{4}{*}{$<0.0001$} & 39.7 \\
\hline 2.1-4 h/day & 33.7 & 29.8 & 43.0 & & 35.6 \\
\hline 4.1-6 h/day & 0.6 & 2.8 & 17.0 & & 7.4 \\
\hline$>6$ h/day & 0.6 & 0.0 & 3.0 & & 1.2 \\
\hline \multicolumn{6}{|l|}{ Fruit vegetable intake } \\
\hline$<5$ servings/day & 95.7 & 94.5 & 75.0 & \multirow[t]{2}{*}{$<0.0001$} & 87.8 \\
\hline$\geq 5$ servings/day & 4.3 & 5.5 & 25.0 & & 12.2 \\
\hline \multicolumn{6}{|l|}{ Processed food intake } \\
\hline$<1$ serving/day & 65.1 & 89.9 & 56.0 & \multirow[t]{2}{*}{$<0.0001$} & 71.5 \\
\hline$\geq 1$ servings/day & 34.9 & 10.1 & 44.0 & & 28.5 \\
\hline Crude waist circumference $(\mathrm{cm})$ & $53.4(7.0)$ & $56.1(7.6)$ & $54.6(5.4)$ & 0.001 & $54.8(6.8)$ \\
\hline Waist-z- scores & $-1.4(5.1)$ & $1.3(6.3)$ & $-0.3(4.3)$ & $<0.0001$ & $0.03(5.4)$ \\
\hline Crude BMI & $14.7(2.1)$ & $14.9(2.4)$ & $14.7(1.7)$ & 0.40 & $14.8(2.1)$ \\
\hline BMI- z- scores & $-1.4(1.1)$ & $-1.3(1.3)$ & $-1.3(0.9)$ & 0.40 & $-1.3(1.1)$ \\
\hline
\end{tabular}

${ }^{a}$ Test of significance for the difference among sites by chi-square test for categorical data and ANOVA for continuous data

${ }^{b}$ SES based on tertiles from total monthly expenditures for Indian sites and total household asset score for Matlab, Bangladesh

Mode of travel to school

Older children aged 10-14 years $(\mathrm{OR}=2.0$; 95 \% CI: 1.3 , $3.0)$ and girls $(\mathrm{OR}=1.7$; $95 \% \mathrm{CI}$ : $1.1,2.5)$ were more likely to use active forms of travel to school than younger children and boys respectively. There was no association between other socio-demographic (household education and 
Table 2 Prevalence of correlates of recommended physical activity status (RPALs) in rural South Asian children aged 5-14 years

\begin{tabular}{|c|c|c|c|}
\hline Percentages (row) & $\begin{array}{l}\text { Active mode of travel } \\
\text { to school }(n=375)\end{array}$ & $\begin{array}{l}\text { Leisure-time physical } \\
\text { activity } \geq 1 \text { h per day }(n=393)\end{array}$ & $\begin{array}{l}\text { Sedentary activity } \\
\leq 2 \mathrm{~h} \text { per day }(n=308)\end{array}$ \\
\hline \multicolumn{4}{|l|}{ Age group } \\
\hline $5-9$ years & 57.5 & 79.8 & 62.1 \\
\hline 10-14 years & 74.2 & 70.4 & 50.5 \\
\hline \multicolumn{4}{|l|}{ Sex } \\
\hline Boys & 61.7 & 80.0 & 59.7 \\
\hline Girls & 72.1 & 66.2 & 51.5 \\
\hline \multicolumn{4}{|l|}{ Site } \\
\hline Matlab & 62.0 & 80.2 & 37.0 \\
\hline Goa & 69.4 & 78.8 & 67.3 \\
\hline Chennai & 69.2 & 59.6 & 64.8 \\
\hline \multicolumn{4}{|l|}{ Highest household education status } \\
\hline $0-5$ years of education & 65.6 & 76.0 & 61.3 \\
\hline 6 to 12 years of education & 68.9 & 76.3 & 54.8 \\
\hline Graduate/Post graduate & 59.7 & 63.2 & 45.8 \\
\hline \multicolumn{4}{|l|}{ Socio-economic status $^{\mathrm{a}}$ (SES) } \\
\hline Low & 69.2 & 70.3 & 56.3 \\
\hline Medium & 64.7 & 75.3 & 57.6 \\
\hline High & 69.1 & 75.6 & 53.1 \\
\hline \multicolumn{4}{|l|}{$\begin{array}{l}\text { Leisure-time physical activity } \\
\text { (at school + at home) }\end{array}$} \\
\hline$<1$ h/day & 67.2 & NA & 53.8 \\
\hline$\geq 1$ h/day & 65.1 & & 55.1 \\
\hline \multicolumn{4}{|l|}{ Sedentary activity } \\
\hline$\leq 2 \mathrm{~h} /$ day & 67.5 & 75.2 & NA \\
\hline$>2$ h/day & 64.7 & 74.2 & \\
\hline \multicolumn{4}{|l|}{ Mode of transport to school } \\
\hline Active transport (walk/bicycle) & NA & 73.9 & 56.8 \\
\hline Motorized transport & & 75.7 & 53.8 \\
\hline \multicolumn{4}{|l|}{ Fruit vegetable intake } \\
\hline$<5$ servings/day & 67.2 & 74.4 & 58.8 \\
\hline$\geq 5$ servings/day & 63.2 & 76.1 & 35.3 \\
\hline \multicolumn{4}{|l|}{ Processed food intake } \\
\hline$<1$ serving/day & 67.6 & 71.6 & 59.5 \\
\hline$\geq 1$ serving/day & 64.5 & 81.7 & 46.2 \\
\hline
\end{tabular}

${ }^{a}$ SES based on tertiles from total monthly expenditures for Indian sites and total household asset score for Matlab, Bangladesh NA Not Applicable

SES status), diet (fruits-vegetables and processed food) and other forms of physical activity (leisure-time activity and sedentary activity).

\section{Leisure-time physical activity}

Boys $(\mathrm{OR}=2.5 ; 95 \% \mathrm{CI}: 1.5,4.0)$ and children living in rural Bangladesh $(\mathrm{OR}=3.0 ; 95 \% \mathrm{CI}: 1.6,5.5)$ reported more leisure-time physical activity than girls and children of other sites respectively. Leisure-time physical activity was lower in children coming from households with higher education status (i.e., at least graduation) $(\mathrm{OR}=0.4 ; 95 \% \mathrm{CI}: 0.2,0.8)$. Children who reported higher levels of leisure-time physical activity were more likely to consume processed food $(\geq 1$ serving per day; $\mathrm{OR}=2.3 ; 95 \% \mathrm{CI}: 1.2$ to 4.1 ). There was no association observed for leisure-time physical 
Table 3 Multivariate adjusted correlates of recommended physical activity status in rural South Asian children aged 5-14 years

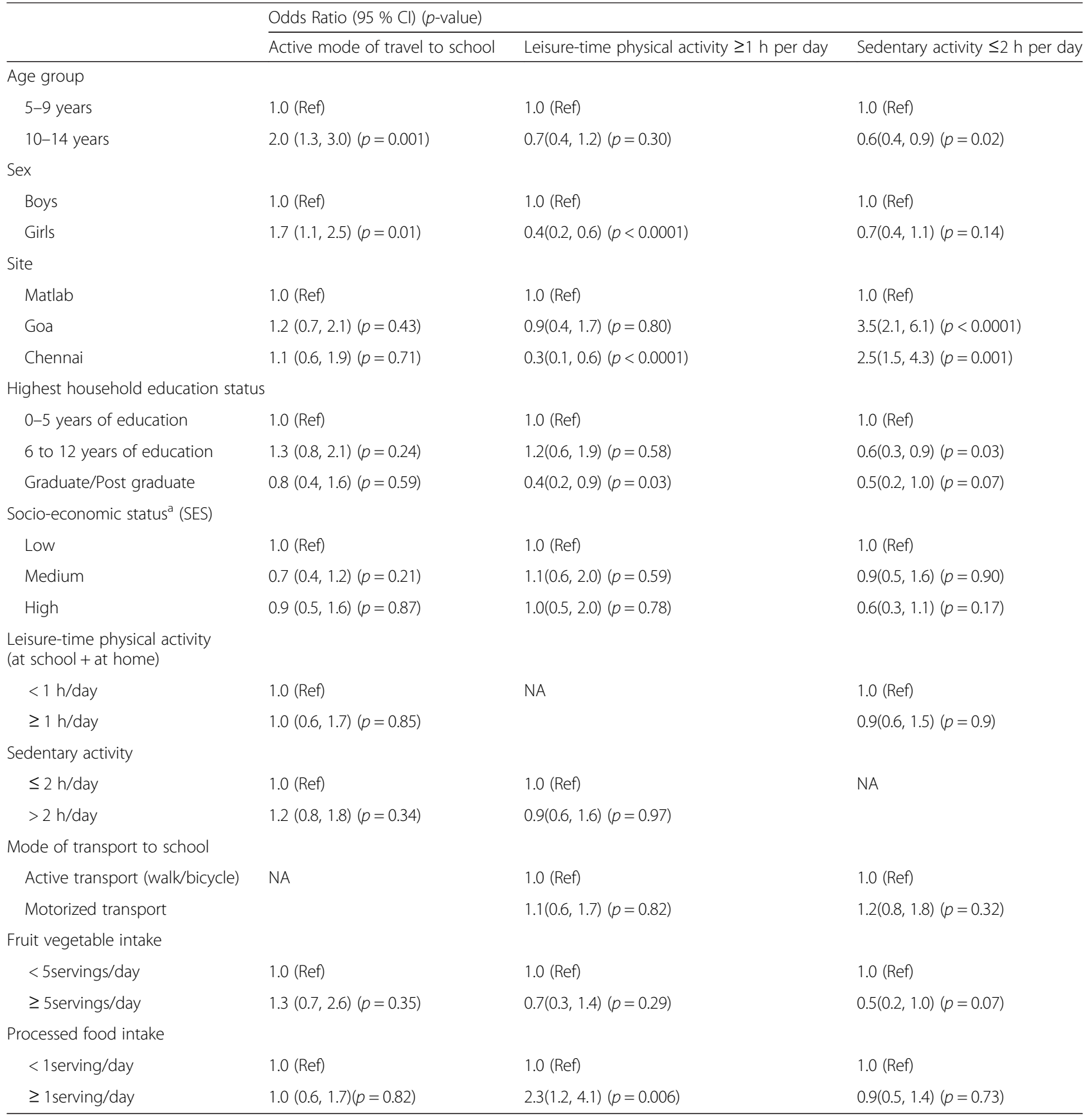

${ }^{a}$ SES based on tertiles from total monthly expenditures for Indian sites and total household asset score for Matlab, Bangladesh; NA Not Applicable

activity with SES based on total monthly expenditure or asset, fruits-vegetables consumption or other forms of physical activity (mode of travel to school and sedentary activity).

\section{Sedentary activity}

Younger children (5-9 years) had less sedentary activity outside school hours than older children $(\mathrm{OR}=1.6 ; 95 \%$
CI: $1.07,2.4)$, or living in Goa (OR $=3.5$; 95 \% CI: 2.1, 6.1) or Chennai (OR $=2.5 ; 95 \%$ CI: $1.5,4.3)$. Children residing in households with lower education status (up to 5 years of education) were less sedentary $(\mathrm{OR}=1.6 ; 95 \% \mathrm{CI}$ : $1.02,2.7)$. There was no association found for sedentary activity with diet (fruits-vegetables and processed food) and other forms of physical activity (mode of travel to school and leisure-time physical activity). 


\section{Associations between physical activity levels and continuous outcome measures (BMI-z- score and waist- z-score)}

In multi-variate analyses, sedentary activity $\leq 2 \mathrm{~h}$ per day was associated with significantly lower BMI ( $\beta$-coefficient $(95 \% \mathrm{CI})=-0.3(-0.5,-0.08), p=0.008)$ and waist-z-scores $(\beta$-coefficient $(95 \% \mathrm{CI})=-1.1(-2.2,-0.07), p=0.03)$ after adjusted for site, SES, highest household education, processed food and fruit-vegetable consumption (Tables 4 and 5). There were no significant associations between leisure-time physical activity or active travel to school and measures of adiposity.

\section{Discussion}

We report the patterns and correlates of recommended physical activity levels (RPALs) in rural South Asian children. Two thirds $(66.7 \%)$ used active mode of travel to school, three quarters (74.6\%) had $\geq 1$ h/day of leisuretime physical activity and $55.7 \%$ had $\leq 2$ h of sedentary activity every day. Older (10 to 14 years of age) and female children travelled actively to school but girls participated in less leisure-time physical activity after school hours (median (IQR):77.1 (45.7, 105.7) min/day vs. 94.6 $(70.0,137.1) \mathrm{min} /$ day in boys; $p<0.0001)$. Although children living in rural Matlab (Bangladesh) reported more leisure-time physical activity daily than children in rural Chennai (India; median (IQR): $94.2(68.5,140) \mathrm{min} /$ day vs. $68.5(45.7,89.6) \mathrm{min} /$ day; $p<0.0001)$, they also reported more sedentary activity outside school hours (median (IQR): $180(90,240) \mathrm{min} /$ day vs. $90(60,125.8) \mathrm{min} /$ day in Goa vs. $120(72.5,150) \mathrm{min} /$ day in Chennai). Children who

Table 4 Associations between physical activity levels and BMI-z-scores in rural South Asian children aged 5-14 years

\begin{tabular}{|c|c|c|}
\hline Type of physical activity & $\begin{array}{l}\text { Age and sex adjusted }^{a} \\
\beta \text {-coefficient }(95 \% \text { Cl) }\end{array}$ & $\begin{array}{l}\text { Multivariate-adjusted } \\
\beta \text {-coefficient (95\% Cl) }\end{array}$ \\
\hline \multicolumn{3}{|l|}{ Mode of travel } \\
\hline Motorized transport & 0.00 (ref) & 0.00 (ref) \\
\hline Active transport & $-0.1(-0.3,0.05)$ & $-0.1(-0.3,0.1)$ \\
\hline$p$-value & 0.14 & 0.28 \\
\hline \multicolumn{3}{|l|}{ Leisure-time physical activity } \\
\hline$<1$ h/day & 0.00 (ref) & 0.00 (ref) \\
\hline$\geq 1$ h/day & $-0.06(-0.3,0.16)$ & $-0.09(-0.3,0.16)$ \\
\hline$p$-value & 0.56 & 0.47 \\
\hline \multicolumn{3}{|l|}{ Sedentary activity } \\
\hline$>2$ h/day & 0.00 (ref) & 0.00 (ref) \\
\hline$\leq 2$ h/day & $-0.2(-0.4,-0.04)$ & $-0.3(-0.5,-0.08)$ \\
\hline$p$-value & 0.01 & 0.008 \\
\hline
\end{tabular}

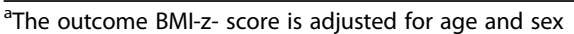

${ }^{\mathrm{b}}$ Adjusted for site, SES (tertiles), Highest household education in categories, processed food consumption as binary, fruit-vegetable consumption as binary, leisure-time physical activity as binary (for mode of travel and sedentary activity), active mode of travel as binary (for leisure-time physical activity and sedentary activity) and sedentary activity as binary (for leisure-time physical activity and active mode of travel)
Table 5 Associations between physical activity levels and waist z-scores in rural South Asian children aged 5-14 years

\begin{tabular}{lll}
\hline Type of physical activity & $\begin{array}{l}\text { Age and sex adjusted } \\
\beta \text {-coefficient }(95 \% \mathrm{Cl})\end{array}$ & $\begin{array}{l}\text { Multivariate-adjusted } \\
\beta \text {-coefficient }(95 \% \mathrm{Cl})\end{array}$ \\
\hline $\begin{array}{lll}\text { Mode of travel } \\
\text { Motorized transport }\end{array}$ & 0.00 (ref) & $0.00($ ref $)$ \\
Active transport & $-0.7(-1.6,0.2)$ & $-0.4(-1.5,0.6)$ \\
$p$-value & 0.15 & 0.37 \\
Leisure-time physical activity & \\
$<1$ h/day & $0.00($ ref $)$ & $0.00($ ref $)$ \\
$\geq 1$ h/day & $0.2(-0.8,1.2)$ & $-0.1(-1.2,1.1)$ \\
$p$-value & 0.70 & 0.86 \\
Sedentary activity & & $0.00($ ref $)$ \\
$>2$ h/day & $0.00($ ref $)$ & $-1.1(-2.2,-0.07)$ \\
$\leq 2$ h/day & $-0.5(-1.4,0.4)$ & 0.03 \\
$p$-value & 0.28 &
\end{tabular}

${ }^{a}$ The outcome waist-z- score is adjusted for age and sex

${ }^{\mathrm{b}}$ Adjusted for site, SES (tertiles), Highest household education in categories, processed food consumption as binary, fruit-vegetable consumption as binary, leisure-time physical activity as binary (for mode of travel and sedentary activity), active mode of travel as binary (for leisure-time physical activity and sedentary activity) and sedentary activity as binary (for leisure-time physical activity and active mode of travel)

belonged to households of higher education (secondary level or higher) were more sedentary and independently reported less leisure-time physical activity. Overall, only $25.2 \%$ of children met the RPALs for all three categories i.e., active travel to school (any), $\geq 1 \mathrm{~h}$ /day leisure-time physical activity and $\leq 2 \mathrm{~h}$ sedentary activity every day.

We are not aware of similar data on rural children in South Asia for comparison. However, with reference to a school-based study from Wardha, Maharashtra, India the prevalence of physical inactivity was high (57.9\%) among children and adolescents aged 6 to 18 years [35]. In this study, although they used WHO - Global Schoolbased Health Survey questionnaire, a modified physical activity score was calculated for each child that was adapted from a scoring system for adults. This could have been the reason for a high prevalence of physical inactivity reported in the study compared to our study. Studies in urban India and Bangladesh have consistently reported higher prevalence of physical inactivity in children and adolescents than levels documented in our study $[1,9,10]$. However, these studies suggest that physical inactivity is more common among girls and older children (22.2-61.9 \% in girls vs. $18.3-47.4 \%$ in boys) $[1,10]$ similar to our study. Studies on South Asian children (Indians and Bangladeshis) in UK found significantly lower levels of physical activity in South Asian children compared to European children with Bangladeshi children as the most sedentary amongst South Asians [36]. Some studies of UK primary school children found no differences between overall levels of physical activity and mode of transport to 
school $[37,38]$ similar to that found in our study, but the results are to be interpreted with caution and cannot be directly applied to children living in rural south Asia.

We found that less sedentary activity ( $\leq 2 \mathrm{~h}$ per day) was associated with significantly lower BMI- and waist-zscores across all sites. Although not significant we found a weak inverse association of active mode of travel to school and greater leisure-time physical activity ( $\geq 1 \mathrm{~h}$ per day) with BMI-z-scores and waist-z-scores across all sites. These findings may reflect that independent of other forms of physical activity, sedentary behaviour is associated with various unfavourable physiological outcomes including weight related problems $[1-3,7]$ as well as the very low prevalence of overweight in our sample. Although the prevalence of over-weight or obesity in rural children aged 6-18 years has been reported at $2.2-9.7 \%$ from two populations of India [39, 40], the association of physical activity patterns and weight outcomes is rarely reported from these rural regions [35]. In our rural children we found TV watching $(49.3 \%)$ as the main sedentary activity followed by reading (43.9\%), which is similar (i.e., long TV viewing) to what is reported in urban children and adolescents of India and Bangladesh [3, 11-18]. Although significant associations of weight-related outcomes and physical activity have been reported in urban children, similar data is distinctly lacking among rural South Asian children.

\section{Strengths/limitations of study}

To our knowledge, these results are the first to report prevalence and correlates of recommended physical activity levels (RPALs) in rural south Asian children. In view of the lack of data from LMICs on rural children, this study is important to inform future monitoring and emerging policies in this area. A major limitation of our study is its cross-sectional nature, which prevents any causal inferences about the associations being observed. Additional limitations include the lack of a gold standard to validate self-reported levels, potential misclassification of physical activity levels and the potential for residual confounding. Another limitation is that the questionnaire grouped public transport (bus) with other 'inactive' modes of motorised transport such as cars and mopeds. Public transport is considered an active mode of travel as it generally involves walking or cycling to transport access points or interchanges [32]. Although we used a validated PA questionnaire, details on chores or activities that children are involved in, which are related to physical activity outside of school may have been missed out. We addressed this aspect in the questionnaire but the information collected reflects more on sports or games rather than chores or household or other work. Moreover, the questionnaire did not allow us for the calculation of metabolic equivalents of activity. These could have reflected in our results.

\section{Implications for policy/practice}

Schools and communities have been identified as important settings for health promotion activities and interventions for children [41]. Thus interventions at both community and school levels are required for adequate policy actions regarding physical activity in children [28]. Further potential concerns with respect to physical activity and policies for South Asian countries include road safety and air pollution in terms of active transport to school, lack of space and child safety. Changing patterns of physical activity due to academic pressures in terms of leisure-time physical activity and lack of awareness regarding sedentary activity should also be considered. Maintaining the relatively high levels of active travel identified in this study through investment in public transport, cycling and walking infrastructure is important [34]. Ongoing monitoring and longitudinal studies of physical activity in rural south Asian children are important to better characterize trends over time and behavioural, social and environmental factors influencing PA in rural settings.

\section{Conclusion}

Only one quarter of children achieved recommended physical activity levels in all three categories of physical activity (i.e., active travel to school, $\geq 1 \mathrm{~h}$ /day leisuretime physical activity and $\leq 2 \mathrm{~h}$ sedentary activity every day) in rural South Asia. Age, gender, household education, and geographical location were associated with RPALs. Less sedentary activity ( $\leq 2 \mathrm{~h}$ per day) may have beneficial effects on adiposity. These findings may indicate that low levels of physical activity and associated risks of overweight and obesity may no longer be restricted to children living in urban, affluent communities in South Asia. Improved understanding of physical activity levels in rural children is important given the rapid social and economic changes occurring in the region.

\section{Abbreviations \\ BMI, body mass index; CDRF, chronic disease risk factor study; LMICs, low-middle income countries; NCD, non-communicable Disease; PA, physical activity; RPAL, recommended physical activity levels; SANCD, South Asia network of chronic disease; SD, standard deviation; SES, socio-economic status; WHO, World Health Organization}

\section{Acknowledgements and Funding \\ This study was funded by The Wellcome Trust - South Asia Network of Chronic Disease Strategic Grant (Grant No. WT 084674). Dr Krithiga Shridhar was supported by a Wellcome Trust Capacity Strengthening Strategic Award Extension phase to the Public Health Foundation of India and a consortium of UK universities (WT084754/Z/08/A).}

Availability of data and materials

Additional information on the CDRF study, instruments/questionnaires as well as data, can be made available to researchers, upon request to the Principal Investigator, Dr. Preet K. Dhillon. 


\section{Authors' contributions}

$\mathrm{KS}, \mathrm{CM}, \mathrm{PKD}$ have carried out the conception and design of the study as well as analysis and interpretation of data. KS, CM have drafted the manuscript and $\mathrm{KS}, \mathrm{CM}, \mathrm{PKD}, \mathrm{AL}$ have revised it critically for important intellectual content. KS, CM, PKD, AL, DA, AD, JW have given final approval of the version to be published. CM agree to be accountable for all aspects of the work in ensuring that questions related to the accuracy or integrity of any part of the work are appropriately investigated and resolved.

\section{Competing interests}

The authors declare that they have no competing interests.

\section{Consent for publication}

Not applicable.

\section{Ethics approval and consent to participate}

The study was approved by Ethics Committees at participating institutes (Public Health Foundation of India (New Delhi, India), Sangath (Goa, India), Voluntary Health Services (Chennai, India), the International Centre for Diarrhoeal Disease Research (Matlab, Bangladesh)) as well as the Indian Council of Medical Research, Health Ministry Screening Committee (No. 50/5/Indo-CVD/DP/2010-NCD-II). Informed written consent was obtained from parents or guardians of all participants, who were ensured that data would remain confidential, accessed by research staff and used for research purposes only. Participants had the right to refuse to answer any questions that were uncomfortable.

\section{Author details}

'Centre for Chronic Conditions and Injuries, Public Health Foundation of India, 4th Floor, Plot.No.47, Sector 44, Gurgaon 122002, Haryana, India. ${ }^{2}$ Department of Primary Care and Public Health, Imperial College, Reynolds Building, Charing Cross Campus, London, UK. ${ }^{3}$ Centre for Global Health Research, Li KaShing Knowledge Institute, St. Michael's Hospital, Toronto, Canada. ${ }^{4}$ Goa Medical College, Sangath, Bardez, Goa, India. ${ }^{5}$ Voluntary Health Services, Chennai, India.

Received: 5 February 2016 Accepted: 22 July 2016

\section{Published online: 02 August 2016}

\section{References}

1. Swaminathan S, Vaz M. Childhood physical activity, sports and exercise and noncommunicable disease: a special focus on India. Indian J Pediatr. 2013:80 Suppl 1:S63-70.

2. Gupta N, Goel K, Shah P, Misra A. Childhood obesity in developing countries: epidemiology, determinants, and prevention. Endocr Rev. 2012:33(1):48-70.

3. Gupta N, Shah P, Nayyar S, Misra A. Childhood obesity and the metabolic syndrome in developing countries. Indian J Pediatr. 2013;80 Suppl 1:S28-37.

4. WorldHealthOrganization, Global Strategy on Diet, Physical Activity and Health Available at: http://www.who.int/dietphysicalactivity/factsheet_ young_people/en/ Accessed on Apr 102015.

5. WorldHealthOrganization, WHO issues guidance on emerging double threat of childhood obesity and undernutrition in low- and middle-income countries, in 2013, available from http://www.who.int/mediacentre/news/ notes/2013/obesity_undernutrition_20130605/en/. Accessed 13 Nov 2014.

6. Selvan MS, Kurpad AV. Primary prevention: why focus on children \& young adolescents? Indian J Med Res. 2004;120(6):511-8.

7. Tremblay MS, LeBlanc AG, Kho ME, Saunders TJ, Larouche R, Colley RC, Goldfield G, Connor Gorber S. Systematic review of sedentary behaviour and health indicators in school-aged children and youth. Int J Behav Nutr Phys Act. 2011:8:98.

8. Larouche R, Saunders TJ, Faulkner G, Colley R, Tremblay M. Associations between active school transport and physical activity, body composition, and cardiovascular fitness: a systematic review of 68 studies. J Phys Act Health. 2014;11(1):206-27.

9. Mistry SK, Puthussery S. Risk factors of overweight and obesity in childhood and adolescence in South Asian countries: a systematic review of the evidence. Public Health. 2015;129(3):200-9.

10. Bhuiyan MU, Zaman S, Ahmed T. Risk factors associated with overweight and obesity among urban school children and adolescents in Bangladesh: a case-control study. BMC Pediatr. 2013;13:72.
11. Singh AK, Maheshwari A, Sharma N, Anand K. Lifestyle associated risk factors in adolescents. Indian J Pediatr. 2006;73(10):901-6.

12. Goyal JP, Kumar N, Parmar I, Shah VB, Patel B. Determinants of overweight and obesity in affluent adolescent in Surat City, south Gujarat region, India. Indian J Community Med. 2011;36(4):296-300.

13. Gulati A, Hochdorn A, Paramesh H, Paramesh EC, Chiffi D, Kumar M, Gregori D, Baldi I. Physical activity patterns among school children in India. Indian J Pediatr. 2014;81 Suppl 1:47-54.

14. Kuriyan R, Bhat S, Thomas T, Vaz M, Kurpad AV. Television viewing and sleep are associated with overweight among urban and semi-urban South Indian children. Nutr J. 2007;6:25

15. Kuriyan R, Thomas T, Sumithra S, Lokesh DP, Sheth NR, Joy R, Bhat S, Kurpad AV. Potential factors related to waist circumference in urban South Indian children. Indian Pediatr. 2012;49(2):124-8.

16. Mukhopadhyay A, Bhadra M, Bose K. Physical exercise, body mass index, subcutaneous adiposity and body composition among Bengalee boys aged 10-17 years of Kolkata, India. Anthropol Anz. 2005;63(1):93-101.

17. Nawab T, Khan Z, Khan IM, Ansari MA. Influence of behavioral determinants on the prevalence of overweight and obesity among school going adolescents of Aligarh. Indian J Public Health. 2014;58(2):121-4.

18. Rani MA, Sathiyasekaran BW. Behavioural determinants for obesity: a crosssectional study among urban adolescents in India. J Prev Med Public Health. 2013:46(4):192-200.

19. Swaminathan S, Selvam S, Thomas T, Kurpad AV, Vaz M. Longitudinal trends in physical activity patterns in selected urban south Indian school children. Indian J Med Res. 2011;134:174-80.

20. Muthuri SK, Wachira LJ, Leblanc AG, Francis CE, Sampson M, Onywera VO, Tremblay MS. Temporal trends and correlates of physical activity, sedentary behaviour, and physical fitness among school-aged children in Sub-Saharan Africa: a systematic review. Int J Environ Res Public Health. 2014;11(3):3327-59.

21. Tomkinson GR, Leger LA, Olds TS, Cazorla G. Secular trends in the performance of children and adolescents (1980-2000): an analysis of 55 studies of the $20 \mathrm{~m}$ shuttle run test in 11 countries. Sports Med. 2003;33(4):285-300.

22. Governmentoflndia, Census of India 2011, in MinistryofHomeAffairsavailable at http://censusindia.gov.in/. Accessed 17 Nov 2014

23. BangladeshBureauofStatistics, Census of Bangladesh 2011. available at http://www.bbs.gov.bd/home.aspx. Accessed 17 Nov 2014.

24. Joshi R, Cardona M, lyengar S, Sukumar A, Raju CR, Raju KR, Raju K, Reddy KS, Lopez A, Neal B. Chronic diseases now a leading cause of death in rural India-mortality data from the Andhra Pradesh Rural Health Initiative. Int J Epidemiol. 2006;35(6):1522-9.

25. Zaman MJ, Patel A, Jan S, Hillis GS, Raju PK, Neal B, Chow CK. Socioeconomic distribution of cardiovascular risk factors and knowledge in rural India. Int J Epidemiol. 2012;41(5):1302-14.

26. Vellakkal S, Subramanian S, Millett C, Basu S, Stuckler D, Ebrahim S. Socioeconomic inequalities in Non-communicable diseases prevalence in India: disparities between self-reported diagnoses and standardized measures. Plos One. 2013;8(7):e68219. doi:10.1371/journal.pone.0068219.

27. Matsuzaki M, Sullivan R, Ekelund U, Krishna KV, Kulkarni B, Collier T, BenShlomo Y, Kinra S, Kuper H. Development and evaluation of the Andhra Pradesh children and parent study physical activity questionnaire (APCAPS-PAQ): a cross-sectional study. BMC Public Health. 2016;16(1):48.

28. Allotey P, Davey T, Reidpath DD. NCDs in low and middle-income countries - assessing the capacity of health systems to respond to population needs. BMC Public Health. 2014;14(2):S1.

29. Lachat C, Otchere S, Roberfroid D, Abdulai A, Seret FM, Milesevic J, Xuereb $\mathrm{G}$, Candeias V, Kolsteren P. Diet and physical activity for the prevention of noncommunicable diseases in low- and middle-income countries: a systematic policy review. PLoS Med. 2013;10(6):e1001465.

30. Gupta A, Priya B, Williams J, Sharma M, Gupta R, Jha DK, Ebrahim S, Dhillon PK. Intra-household evaluations of alcohol abuse in men with depression and suicide in women: a cross-sectional community-based study in Chennai, India. BMC Public Health. 2015;15:636.

31. McKay AJ, Laverty AA, Shridhar K, Alam D, Dias A, Williams J, Millett C, Ebrahim S, Dhillon PK. Associations between active travel and adiposity in rural India and Bangladesh: a cross-sectional study. BMC Public Health. 2015;15:1087.

32. Sullivan R, Kinra S, Ekelund U, Bharathi AV, Vaz M, Kurpad A, Collier T, Reddy KS, Prabhakaran D, Ebrahim S, Kuper H. Evaluation of the Indian migration study physical activity questionnaire (IMS-PAQ): a cross-sectional study. Int J Behav Nutr Phys Act. 2012;9:13. 
33. WorldHealthOrganisation, Global school-based student health survey available at http://www.who.int/chp/gshs/india/en/Accessed 5 May 2016.

34. WorldHealthOrganisation, Child Growth Standards. available at http://www.who.int/childgrowth/software/en/; Accessed 5 May 2016.

35. Dongre AR, Deshmukh PR, Garg BS. Health-promoting school initiative in Ashram schools of Wardha district. Natl Med J India. 2011;24(3):140-3.

36. Fischbacher CM, Hunt S, Alexander L. How physically active are South Asians in the United Kingdom? A literature review. J Public Health (Oxf). 2004:26(3):250-8.

37. Ford P, Bailey R, Coleman D, Woolf-May K, Swaine I. Activity levels, dietary energy intake, and body composition in children who walk to school. Pediatr Exerc Sci. 2007;19(4):393-407.

38. Metcalf B, Voss L, Jeffery A, Perkins J, Wilkin T. Physical activity cost of the school run: impact on schoolchildren of being driven to school (EarlyBird 22). BMJ. 2004;329(7470):832-3.

39. Deshmukh PR, Gupta SS, Bharambe MS, Dongre AR, Maliye C, Kaur S, Garg BS. Nutritional status of adolescents in rural Wardha. Indian J Pediatr. 2006;73(2):139-41.

40. Ghosh A. Rural-urban comparison in prevalence of overweight and obesity among children and adolescents of Asian Indian origin. Asia Pac J Public Health. 2011;23(6):928-35.

41. Shah P, Misra A, Gupta N, Hazra DK, Gupta R, Seth P, Agarwal A, Gupta AK, Jain A, Kulshreshta A, Hazra N, Khanna P, Gangwar PK, Bansal S, Tallikoti P, Mohan I, Bhargava R, Sharma R, Gulati S, Bharadwaj S, Pandey RM, Goel K. Improvement in nutrition-related knowledge and behaviour of urban Asian Indian school children: findings from the 'Medical education for children/ Adolescents for Realistic prevention of obesity and diabetes and for healthy aGeing' (MARG) intervention study. Br J Nutr. 2010;104(3):427-36.

\section{Submit your next manuscript to BioMed Central and we will help you at every step:}

- We accept pre-submission inquiries

- Our selector tool helps you to find the most relevant journal

- We provide round the clock customer support

- Convenient online submission

- Thorough peer review

- Inclusion in PubMed and all major indexing services

- Maximum visibility for your research

Submit your manuscript at www.biomedcentral.com/submit

C Biomed Central 